\title{
Sodium channels as targets for volatile anesthetics
}

\author{
Karl F. Herold ${ }^{1}$ and Hugh C. Hemmings Jr. ${ }^{1,2 *}$ \\ 1 Department of Anesthesiology, Weill Cornell Medical College, New York, NY, USA \\ 2 Department of Pharmacology, Weill Cornell Medical College, New York, NY, USA
}

\section{Edited by:}

Mohamed Chahine, Laval University,

Canada

Reviewed by:

Xander H. T. Wehrens, Baylor College

of Medicine, USA

Clemens Möller,

Albstadt-Sigmaringen University,

Germany

\section{${ }^{*}$ Correspondence:}

Hugh C. Hemmings Jr., Departments of Anesthesiology and Pharmacology, Weill Cornell Medical College, Box-50, LC-203, 1300 York Avenue, New York, NY 10065, USA.

e-mail: hchemmi@med.cornell.edu
The molecular mechanisms of modern inhaled anesthetics are still poorly understood although they are widely used in clinical settings. Considerable evidence supports effects on membrane proteins including ligand-and voltage-gated ion channels of excitable cells. $\mathrm{Na}^{+}$channels are crucial to action potential initiation and propagation, and represent potential targets for volatile anesthetic effects on central nervous system depression. Inhibition of presynaptic $\mathrm{Na}^{+}$channels leads to reduced neurotransmitter release at the synapse and could therefore contribute to the mechanisms by which volatile anesthetics produce their characteristic end points: amnesia, unconsciousness, and immobility. Early studies on crayfish and squid giant axon showed inhibition of $\mathrm{Na}^{+}$currents by volatile anesthetics at high concentrations. Subsequent studies using native neuronal preparations and heterologous expression systems with various mammalian $\mathrm{Na}^{+}$channel isoforms implicated inhibition of presynaptic $\mathrm{Na}^{+}$channels in anesthetic actions at clinical concentrations. Volatile anesthetics reduce peak $\mathrm{Na}^{+}$current $\left(/_{\mathrm{Na}}\right)$ and shift the voltage of half-maximal steady-state inactivation $\left(h_{\infty}\right)$ toward more negative potentials, thus stabilizing the fastinactivated state. Furthermore recovery from fast-inactivation is slowed, together with enhanced use-dependent block during pulse train protocols. These effects can depress presynaptic excitability, depolarization and $\mathrm{Ca}^{2+}$ entry, and ultimately reduce transmitter release. This reduction in transmitter release is more potent for glutamatergic compared to GABAergic terminals. Involvement of $\mathrm{Na}^{+}$channel inhibition in mediating the immobility caused by volatile anesthetics has been demonstrated in animal studies, in which intrathecal infusion of the $\mathrm{Na}^{+}$channel blocker tetrodotoxin increases volatile anesthetic potency, whereas infusion of the $\mathrm{Na}^{+}$channels agonist veratridine reduces anesthetic potency. These studies indicate that inhibition of presynaptic $\mathrm{Na}^{+}$channels by volatile anesthetics is involved in mediating some of their effects.

Keywords: sodium channels, volatile anesthetics, presynaptic, anesthetic mechanism

\section{BACKGROUND}

It has been over 160 years since the use of diethyl ether as a general anesthetic was publicly demonstrated, yet our mechanistic understanding of these vitally important drugs lags far behind that of most other major drug classes. Most modern inhaled anesthetics are derivatives of ether, and over the years have been developed to have improved pharmacokinetics, but they are still plagued by a lack of specificity with significant cardiovascular and respiratory side effects. It remains unclear how these drugs produce general anesthesia, a pharmacologically induced coma characterized by amnesia, unconsciousness, and immobility in response to painful stimuli (Hemmings et al., 2005b). Studies into their molecular mechanisms in the 1960s, which have their origins in the MeyerOverton correlation of anesthetic potency with lipophilicity from 1900, led to a lipid-based theory involving a unitary mechanism of non-specific actions on the lipid bilayer (Meyer, 1899; Overton, 1901).

With technical advances in biochemistry and biophysics, specific targets were studied and identified. Pioneering studies showed that anesthetic interactions with proteins themselves, not necessarily involving lipid interactions, could explain anesthetic effects at a biochemical level (Franks and Lieb, 1994). Animal studies showed that volatile anesthetics produce their immobilizing effects primarily by actions on the spinal cord (Antognini and Schwartz, 1993; Rampil et al., 1993), whereas unconsciousness and amnesia involve actions at supra-spinal centers (Eger et al., 2008). Membrane proteins including ion channels have been implicated as key mediators of the depressive effects of anesthetics on neuronal function. Many potential targets have been identified, and it has become clear that anesthetics act at multiple distinct targets in the central nervous system to produce the various component effects of the anesthetic state (multi-site hypothesis).

\section{MECHANISMS OF GENERAL ANESTHETIC EFFECTS ON THE CENTRAL NERVOUS SYSTEM}

The idea of general anesthetics acting both on excitatory and inhibitory synaptic transmission has lead to many studies pointing out the complexity of anesthetic mechanisms (Rudolph and Antkowiak, 2004; Hemmings et al., 2005b; Franks, 2006). General anesthetics, including both volatile and intravenous anesthetics, enhance synaptic inhibition via postsynaptic $\gamma$-aminobutyric acid type $\mathrm{A}\left(\mathrm{GABA}_{\mathrm{A}}\right)$ receptor modulation (Nicoll et al., 1975; 
Zimmerman et al., 1994). More recent studies also point out the importance of extrasynaptic $\mathrm{GABA}_{\mathrm{A}}$ receptors as a target of anesthetics by potentiating tonic inhibitory currents (Orser, 2006; Rau et al., 2009) and by enhancing the release of GABA by a presynaptic increase in miniature inhibitory postsynaptic current (mIPSC) frequency (Nishikawa and MacIver, 2001). Depression of excitatory transmission by presynaptic effects is another target of anesthetic action (Perouansky et al., 1995; Maclver et al., 1996; Ouanonou et al., 1999; Wakasugi et al., 1999). Both volatile and intravenous anesthetics reduce excitatory postsynaptic potentials (EPSPs) in neurons, an effect most likely due to presynaptic mechanisms (Weakly, 1969; Richards and White, 1975; Kullmann et al., 1989; Berg-Johnsen and Langmoen, 1992). Recent evidence suggests that inhibition of glutamatergic synaptic transmission through $N$-methyl-D-aspartate (NMDA)-type glutamate receptor blockade by inhaled anesthetics might also contribute to depression of excitatory transmission (Dickinson et al., 2007; Haseneder et al., 2008).

It is now evident that ligand-gated ion channels are major targets for general anesthetics (Franks and Lieb, 1994). Both inhibition of excitatory NMDA receptors and potentiation of inhibitory $\mathrm{GABA}_{\mathrm{A}}$ and glycine receptors have come under scrutiny as important targets for both intravenous and inhaled anesthetic effects on synaptic transmission (Franks, 2006). These receptors are found throughout the central nervous system and are major transducers of excitatory and inhibitory neurotransmitter signaling.

Second-messenger regulated protein phosphorylation of $\mathrm{Na}^{+}$ channels has been implicated as another possible target of volatile anesthetics. Halothane increases both purified (Hemmings and Adamo, 1994) and endogenous (Hemmings and Adamo, 1996) brain protein kinase $\mathrm{C}$ (PKC) activity. Phosphorylation of $\mathrm{Na}^{+}$ channels by $\mathrm{PKC}$ and PKA reduces $\mathrm{Na}^{+}$channel activity by altering channel kinetics, for example by slowing inactivation, and is therefore an important component of neuromodulation (Cantrell and Catterall, 2001). It is possible that some of the inhibitory effects of volatile anesthetics on $\mathrm{Na}^{+}$channel activity are mediated through PKC phosphorylation.

More recent studies have extended the range of likely anesthetic targets to include neuronal nicotinic acetylcholine receptors (Flood et al., 1997), two pore domain $\mathrm{K}_{2 \mathrm{P}}$ channels and $\mathrm{K}^{+}$leak channels (Patel and Honore, 2001; Sirois et al., 2002), and presynaptic voltage-gated $\mathrm{Na}^{+}$channels. This review considers $\mathrm{Na}^{+}$ channels as targets for the effects of volatile anesthetics (inhaled alkane and ether derivatives).

\section{PRESYNAPTIC $\mathrm{Na}^{+}$CHANNELS AS ANESTHETIC TARGETS}

$\mathrm{Na}^{+}$channels play a crucial role in cell-to-cell communication, as they are involved in initiating and propagating action potentials in excitable cells throughout the nervous system (Hodgkin and Huxley, 1952). Early reports in the 1970s associated the effects of volatile anesthetics on lipid bilayer properties to alterations of certain membrane bound ion channels, in particular voltage-gated $\mathrm{Na}^{+}$channels (Figure 1).

These reports were among the first to hypothesize a specific ion channel $\left(\mathrm{Na}^{+}\right.$channels) as a potential target of volatile anesthetics, though at that time no specific binding site or specific mechanism could be identified. Early studies on the effects of general

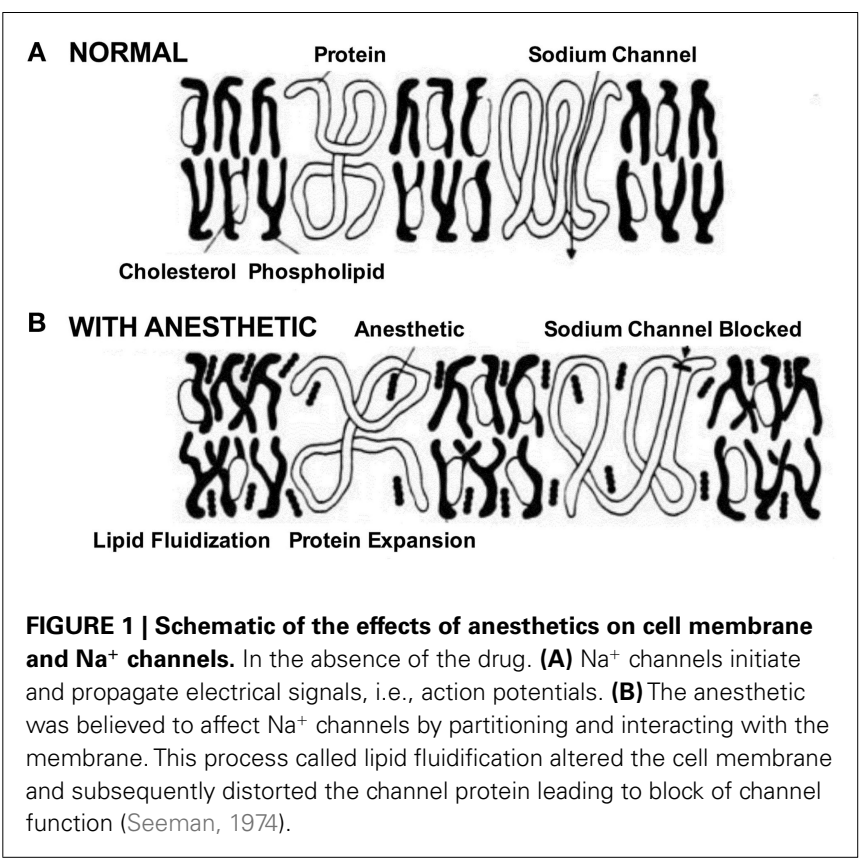

anesthetics on $\mathrm{Na}^{+}$and $\mathrm{K}^{+}$currents in the crayfish or squid giant axon showed inhibition of peak $\mathrm{Na}^{+}\left(I_{\mathrm{Na}}\right)$ current and effects on channel recovery, but in these preparations inhibition occurred at relatively high concentrations (Bean et al., 1981; Haydon and Simon, 1988). Subsequent studies examined the effects of various volatile anesthetics on mammalian brain derived $\mathrm{Na}^{+}$channels heterologously expressed in mammalian cell lines (Rehberg et al., 1996). Inhibition of peak $I_{\mathrm{Na}}$ due to stabilization of the inactivated state of $\mathrm{Na}^{+}$channels was evident as a hyperpolarizing "left-shift" in steady-state (or $\left.h_{\infty}\right)$ inactivation. These experiments were among the first to demonstrate inhibition of neuronal $\mathrm{Na}^{+}$ channels by volatile anesthetics. The sensitivity of $\mathrm{Na}^{+}$channels to clinically relevant concentrations of volatile anesthetics was confirmed in various in vitro expression systems and was subsequently extended to more physiologically relevant neuronal preparations.

Electrophysiological recordings performed in isolated rat neurohypophysial nerve terminals, an experimentally accessible nerve terminal preparation, showed that clinically relevant concentrations of isoflurane inhibited peak $I_{\mathrm{Na}}$ in nerve terminals in a concentration- and voltage-dependent manner (Ouyang et al., 2003; Figure 2A, upper panel). Similar to heterologous expression systems, a left-shift in the voltage-dependence of steady-state inactivation demonstrated stabilization of the fast-inactivated state. These results support the hypothesis that volatile anesthetics depress excitatory synaptic transmission by inhibiting presynaptic voltage-gated $\mathrm{Na}^{+}$channels. In addition, in the rat neurohypophysial nerve terminal preparation, isoflurane inhibited action potential amplitude and increased action potential halfwidth (Ouyang and Hemmings, 2005; Figure 2A, lower panel). The underlying current mediating the fast and rising depolarizing phase of the action potential is carried by tetrodotoxin (TTX)sensitive $\mathrm{Na}^{+}$channels, which were inhibited by isoflurane using a voltage-stimulus based on an averaged action potential. The effects of non-immobilizers (structurally similar compounds without 
anesthetic properties) in rat dorsal root ganglion neurons showed that compound F3, an anesthetic fluorinated cyclobutane, inhibited $\mathrm{Na}^{+}$channels similar to the effects of conventional volatile anesthetics, but the non-anesthetic (non-immobilizer) fluorinated cyclobutane F6 had only minimal effects (Ratnakumari et al., 2000; Figure 4A). These findings support the role of $\mathrm{Na}^{+}$channels as molecular targets for volatile anesthetic action.

Studies investigating subtype-specific effects of volatile anesthetics revealed small, but potentially significant, differences in isoflurane potency with $\mathrm{IC}_{50}$ values ranging from 0.45 to $0.7 \mathrm{mM}$ (at $V_{\mathrm{h}}-70 \mathrm{mV}$ ) on $\mathrm{Na}_{\mathrm{v}} 1.2, \mathrm{Na}_{\mathrm{v}} 1.4, \mathrm{Na}_{\mathrm{v}} 1.5$ expressed in Chinese hamster ovary cells (Ouyang and Hemmings, 2007). Despite the small potency differences, there were differences between isoforms in recovery from fast-inactivation tested by a double-pulse protocol. The effect of isoflurane on channel recovery was greatest in $\mathrm{Na}_{\mathrm{v}} 1.2$, a major brain isoform (Figure 2B). Another study in which subtypes $\mathrm{Na}_{\mathrm{v}} 1.2, \mathrm{Na}_{\mathrm{v}} 1.4, \mathrm{Na}_{\mathrm{v}} 1.6$, and TTX-resistant $\mathrm{Na}_{\mathrm{v}} 1.8$ were expressed (with and without $\beta 1$ subunit co-expression) in Xenopus oocytes also revealed that $\mathrm{Na}_{\mathrm{v}} 1.2, \mathrm{Na}_{\mathrm{v}} 1.4, \mathrm{Na}_{\mathrm{v}} 1.6$ were sensitive to isoflurane, whereas the TTX-resistant subtype $\mathrm{Na}_{\mathrm{v}} 1.8$, which is highly expressed in dorsal root ganglion nociceptive neurons, was insensitive (Shiraishi and Harris, 2004). Nerve terminals of nociceptive sensory neurons are the (main) origin of neuropathic and inflammatory pain signals (Dib-Hajj et al., 2010), but the pro- or anti-nociceptive effects of volatile anesthetics are not clearly defined. It is evident that these nociceptive neurons carry a distinct selection of $\mathrm{Na}^{+}$channel subtypes related to pain signaling (e.g., $\mathrm{Na}_{\mathrm{v}} 1.7, \mathrm{Na}_{\mathrm{v}} 1.8, \mathrm{Na}_{\mathrm{v}} 1.9$; see review Dib-Hajj et al., 2010). Subsequently, $\mathrm{Na}_{\mathrm{v}} 1.8$ expressed in mammalian neuronal cells revealed concentration- and voltage-dependent inhibition of $\mathrm{Na}_{\mathrm{v}} 1.8$ by clinically relevant concentrations of isoflurane similar to other subtypes (Herold et al., 2009; Figure 3A, upper panel). This demonstrates the importance of choosing a suitable expression system for pharmacological studies of ion channels. In this case the neuronal cell line ND7/23, a hybrid cell line between rat dorsal root ganglion neurons and mouse neuroblastoma cells, may have provided auxiliary $\beta$-subunits or other neuron-specific signaling pathways that are important for inhibition by anesthetics. A comparative study showing the effects of several different volatile anesthetics on heterologously expressed $\mathrm{Na}^{+}$channels in mammalian cells revealed that desflurane, a highly fluorinated inhaled anesthetic, had the strongest effect on peak $I_{\mathrm{Na}}$ inhibition, but all agents in this class were effective at clinically relevant concentrations (Ouyang et al., 2009; Figure 3B). In contrast, the
A
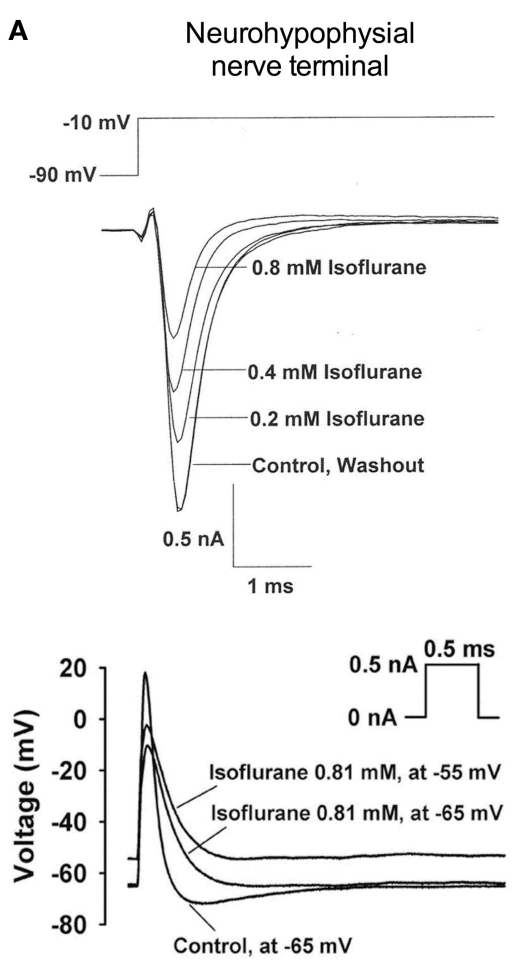

FIGURE 2 | Volatile anesthetics inhibit $\mathrm{Na}^{+}$channels in various expression systems. [(A), upper panel] Electrophysiological recordings of isolated rat neurohypophysial nerve terminals show a reversible block of $\mathrm{Na}^{+}$ currents and [(A), lower panel] action potentials evoked by small current injections at clinically relevant concentrations of isoflurane (Ouyang et al., 2003; Ouyang and Hemmings, 2005). (B) Effects of isoflurane on channel recovery from fast-inactivation of three different $\mathrm{Na}^{+}$channel isoforms
B Recovery from fast-inactivation
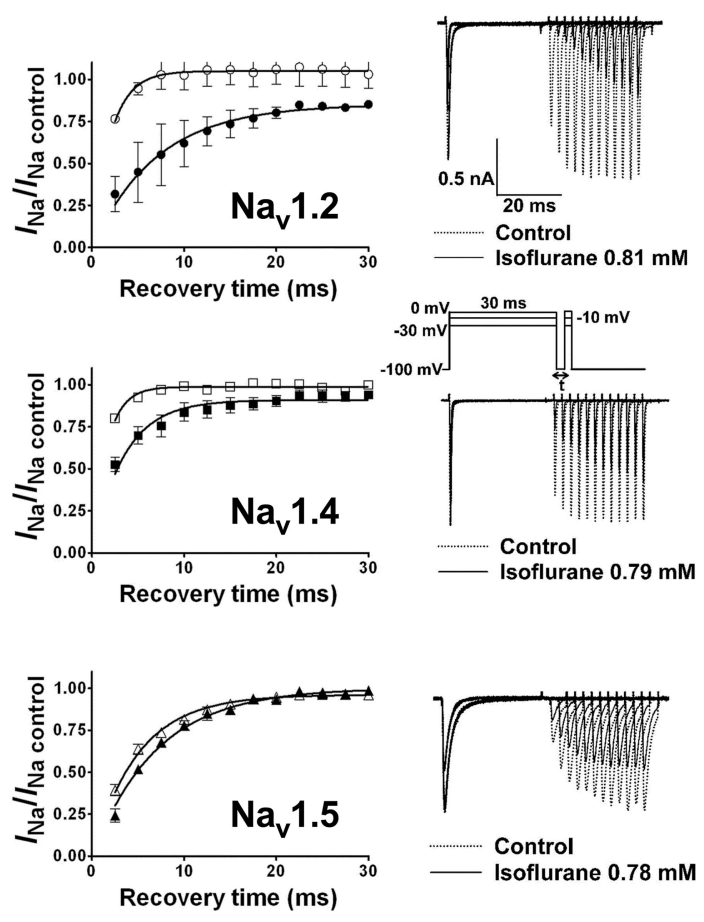

heterologously expressed in mammalian cells. Recovery was assessed using a two-pulse protocol with a 30-ms conditioning pulse followed by a variable recovery interval of up to $30 \mathrm{~ms}$, and then a 5 -ms test pulse to peak activation voltages. The time course of channel recovery from fast-inactivation was well fitted by a monoexponential function [(B), left panels]. Representative current traces for a holding potential $\left(V_{h}\right)$ of $-100 \mathrm{mV}$ are shown for all three subtypes [(B), right panels; Ouyang and Hemmings, 2007]. 


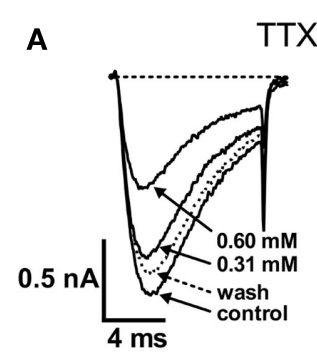

TTX-r $\mathrm{Na}_{\mathrm{v}} 1.8$
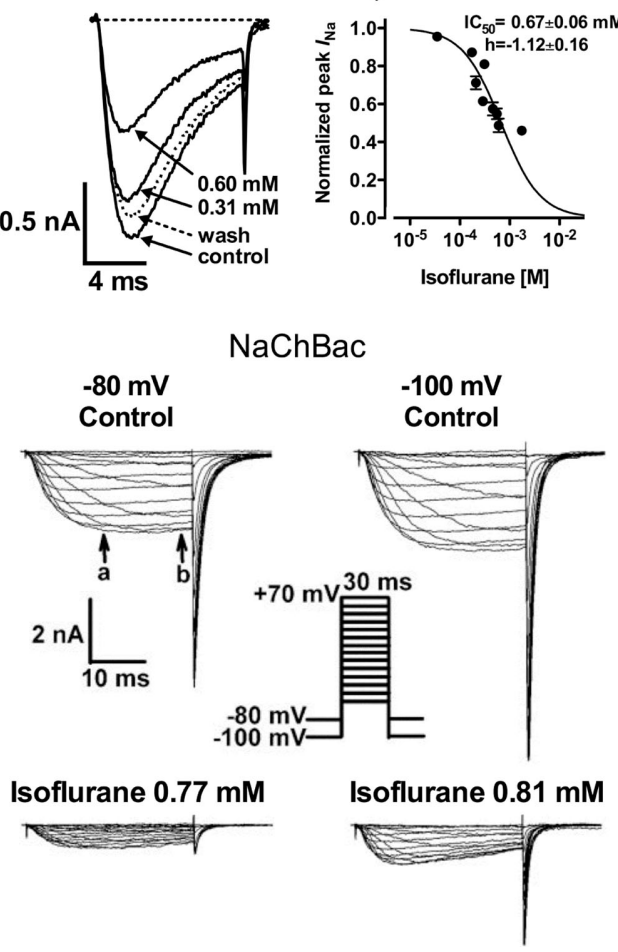

FIGURE 3 | [(A), upper panel] Concentration-dependent inhibition of tetrodotoxin-resistant (TTX-r) $\mathrm{Na}_{v} 1.8$ by isoflurane. Current traces of TTX-r $\mathrm{Na}_{\mathrm{v}} 1.8$ are shown in the absence or presence of two isoflurane concentrations. Normalized peak $I_{\mathrm{Na}}$ values for TTX-r Na 1.8 were fitted to the Hill equation to yield $I_{50}$ values and Hill slopes (Herold et al., 2009). [(A), lower panel] Effects of isoflurane on NaChBac expressed in HEK293 cells. Families of current traces are shown at two different holding potentials $\left(V_{h}\right)$ in the absence or presence of isoflurane.

\section{B Comparative study}

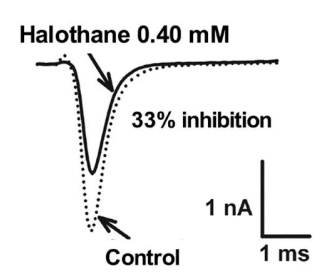

Enflurane 0.81 $\mathrm{mM}$

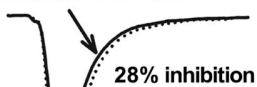

$28 \%$ inhibition
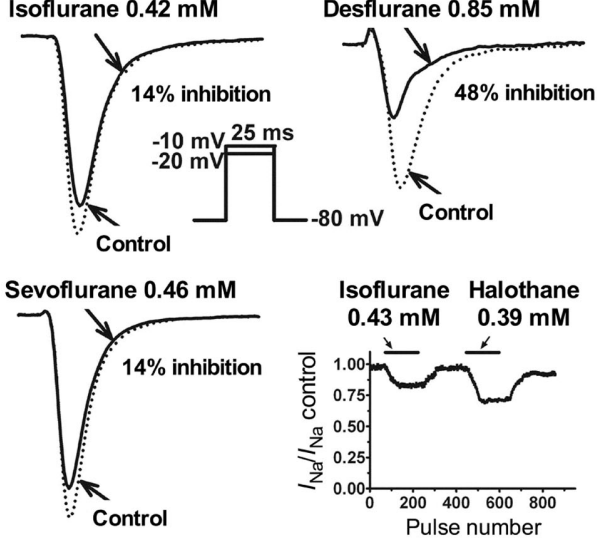

Isoflurane significantly inhibited $I_{\mathrm{Na}}$ from a $V_{\mathrm{h}}$ of either -80 or $-100 \mathrm{mV}$ (Ouyang et al., 2007). (B) Inhibition of $\mathrm{Na}_{\mathrm{v}} 1.4$ by equipotent concentrations of various inhaled anesthetics. Peak $I_{\mathrm{Na}}$ were recorded from a holding potential of $-80 \mathrm{mV}$ by $25-\mathrm{ms}$ test steps as shown in the inset. The effects of clinically equipotent concentrations of halothane, isoflurane, sevoflurane, enflurane, and desflurane are shown in these representative traces. Desflurane had the greatest effect of peak $I_{\mathrm{Na}}$ reduction.

of the differential effects of these structurally different compounds has yet to be elucidated. Differences also exist in the potency of volatile anesthetic inhibition of specific $\mathrm{Na}^{+}$channel subtypes (Ouyang et al., 2009), but again the mechanisms for these differences have to be studied in more detail. Such differences might underlie region-specific presynaptic effects of volatile anesthetics on neurotransmitter release (Westphalen et al., 2010, 2011).

\section{$\mathrm{Na}^{+}$CHANNEL INHIBITION LEADS TO INHIBITION OF NEUROTRANSMITTER RELEASE BY ANESTHETICS}

A physiological consequence of presynaptic $\mathrm{Na}^{+}$channel inhibition is depression of presynaptic action potential generation and conduction. Considerable evidence indicates that volatile anesthetics inhibit neurotransmitter release, and that this is due in part to inhibition of presynaptic $\mathrm{Na}^{+}$channels. Volatile anesthetics preferentially inhibit 4 -aminopyridine (4AP)-evoked release of glutamate compared to GABA from isolated rat cortical nerve terminals (Westphalen and Hemmings, 2006). Action potentialevoked depolarization and release can be pharmacologically mimicked by $4 \mathrm{AP}$, a K ${ }^{+}$channel blocker, while $\mathrm{Na}^{+}$channel independent release can be elicited by depolarization with elevated extracellular $\mathrm{K}^{+}$(Tibbs et al., 1989). Using this approach, 4AP-evoked 


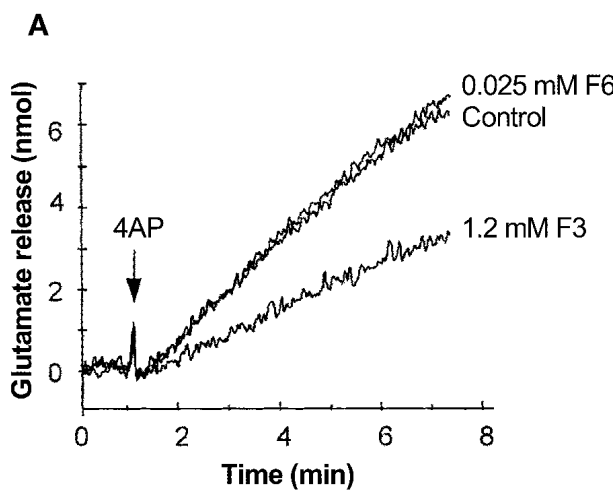

FIGURE 4 | Volatile anesthetics inhibit neurotransmitter release in nerve terminals. (A) Effects of the anesthetic compound F3 and the non-immobilizer F6 on 4-aminopyridine- (4AP) evoked glutamate release from cortical synaptosomes. The anesthetic cyclobutane F3 significantly inhibits glutamate release, whereas the non-anesthetic (non-immobilizer) cyclobutane F6 shown no inhibitory effect (Ratnakumari et al., 2000). (B)

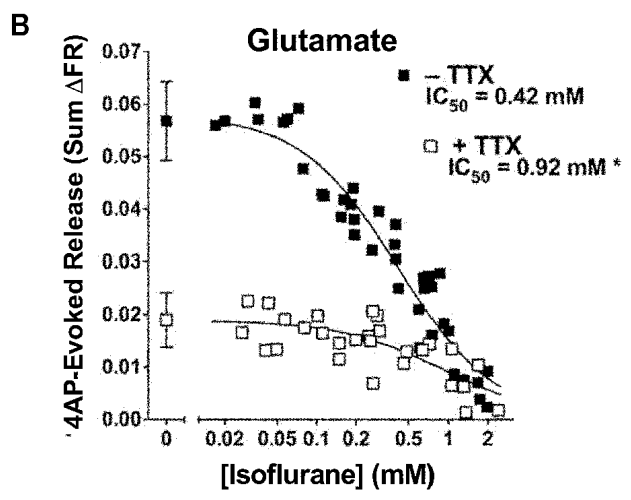

Isoflurane inhibition of 4AP-evoked glutamate release from rat cortical nerve terminals in the absence or presence of tetrodotoxin (TTX, $1 \mu \mathrm{M}$ ). The potency of isoflurane inhibition is much greater in the absence of the $\mathrm{Na}^{+}$channel blocker TTX indicating a strong involvement of $\mathrm{Na}^{+}$channels in inhibition of neurotransmitter release by volatile anesthetics Mestphalen et al., 2011). release is significantly more sensitive to inhibition by volatile anesthetics as compared to $\mathrm{KCl}$-evoked release, supporting a role for blockade of presynaptic $\mathrm{Na}^{+}$channels in the inhibitory effects of the anesthetics (Schlame and Hemmings, 1995; Westphalen and Hemmings, 2003). Interestingly, inhibition of glutamate release occurs with about $50 \%$ greater potency than inhibition of GABA release, consistent with pharmacologically relevant transmitterspecific specializations in neurotransmitter release regulation, perhaps involving differential coupling to $\mathrm{Na}^{+}$channels (Westphalen et al., 2010; Figure 4B). There is also evidence that volatile anesthetics inhibit neurotransmitter release in a brain region-specific manner (Westphalen et al., 2011), which suggests diversity in presynaptic $\mathrm{Na}^{+}$channel subtype expression and/or coupling to release (Westphalen et al., 2010).

Further experiments have examined the effects of volatile anesthetics on synaptic vesicle exocytosis, detected using fluorescence imaging, in cultured rat hippocampal neurons. This preparation allows electrical stimulation of release, and showed concentrationdependent and reversible inhibition of action potential-evoked exocytosis by isoflurane. Involvement of presynaptic $\mathrm{Na}^{+}$channels is supported by the observation that exocytosis, evoked by depolarization with elevated extracellular $\mathrm{K}^{+}$(which is insensitive to TTX), was relatively insensitive to isoflurane (Hemmings et al., 2005a). Isoflurane has also shown to inhibit excitatory postsynaptic currents (EPSCs) in the rat calyx of Held due to inhibition of neurotransmitter release caused by a reduction of presynaptic action potential amplitude (Wu et al., 2004). These effects of volatile anesthetics on synaptic transmission result primarily from inhibition of action potential-evoked synaptic vesicle exocytosis, most likely as a result of $\mathrm{Na}^{+}$channel blockade upstream of $\mathrm{Ca}^{2+}$ entry and exocytosis.

In vivo studies on rodents have implicated spinal $\mathrm{Na}^{+}$channels in immobilization, a major component of general anesthesia. Intravenous infusion of lidocaine, a classical local anesthetic, or intrathecal administration of riluzole, another potent $\mathrm{Na}^{+}$channel inhibitor, significantly increases the potency of volatile anesthetics as immobilizers (Xing et al., 2003; Zhang et al., 2007). The role of $\mathrm{Na}^{+}$channels in volatile anesthetic-mediated immobility is further supported by the observation that intrathecal infusion of the $\mathrm{Na}^{+}$channel activator veratridine, a plant neurotoxin that binds to site 2 and stabilizes the open state (Ulbricht, 1998), reduces the potency of isoflurane (Zhang et al., 2008), while intrathecal infusion of TTX increases the potency of isoflurane, and reverses the effect of veratridine (Zhang et al., 2010). Taken together, these results indicate that inhibition of spinal voltage-gated $\mathrm{Na}^{+}$channels by inhaled anesthetics is likely an important mechanism in anesthetic immobility.

\section{NON-ANESTHETIC EFFECTS OF VOLATILE ANESTHETICS}

A major side effect of volatile anesthetics is cardiovascular depression. Multiple ion channel types expressed in cardiomyocytes contribute to action potential conduction and myocardial contractility. Inhibition of L-type $\mathrm{Ca}^{2+}$ currents or voltage-gated transient and sustained outward $\mathrm{K}^{+}$currents by volatile anesthetics can lead to reduced contractility and delayed repolarization with mismatch of action potential duration (Huneke et al., 2004). In cardiac $\mathrm{Na}^{+}$ channels $\left(\mathrm{Na}_{\mathrm{v}} 1.5\right)$, volatile anesthetics at clinically relevant concentrations inhibit peak $I_{\mathrm{Na}}$ and affect steady-state fast- as well as slow-inactivation (Stadnicka et al., 1999; Ouyang and Hemmings, 2007). This can, in combination with other cardiodepressant drugs, slow conduction and lead to tachyarrhythmias. $\mathrm{Na}^{+}$ channels have also been implicated as potential targets for neuroprotection by volatile anesthetics (Hemmings, 2004). The possible role of voltage-gated $\mathrm{Na}^{+}$channels and other beneficial and detrimental side effects of volatile anesthetics in brain and other organs cannot be excluded.

\section{CONCLUSION}

Both electrophysiological and functional studies indicate that presynaptic voltage-gated $\mathrm{Na}^{+}$channels are inhibited by clinically used concentrations of volatile anesthetics. This leads to reductions in evoked neurotransmitter release that is both brain 
region and neurotransmitter selective. The selective inhibition of glutamate release underlies a reduction in excitatory synaptic transmission with resultant nervous system depression. Detailed information regarding the presynaptic localization, function, and regulation of specific $\mathrm{Na}^{+}$channel subtypes is currently lacking. Further studies are necessary to identify the roles of specific presynaptic $\mathrm{Na}^{+}$channel subtypes in mediating neurotransmitter

\section{REFERENCES}

Antognini, J. F., and Schwartz, K. (1993). Exaggerated anesthetic requirements in the preferentially anesthetized brain. Anesthesiology 79, 1244-1249.

Bean, B. P., Shrager, P., and Goldstein, D. A. (1981). Modification of sodium and potassium channel gating kinetics by ether and halothane. J. Gen. Physiol. 77, 233-253.

Berg-Johnsen, J., and Langmoen, I. A. (1992). The effect of isoflurane on excitatory synaptic transmission in the rat hippocampus. Acta Anaesthesiol. Scand. 36, 350-355.

Cantrell, A., and Catterall, W. (2001). Neuromodulation of $\mathrm{Na}+$ channels: an unexpected form of cellular plasticity. Nat. Rev. Neurosci. 2, 397-407.

Dib-Hajj, S. D., Cummins, T. R., Black, J. A., and Waxman, S. G. (2010). Sodium channels in normal and pathological pain. Annu. Rev. Neurosci. 33, 325-347.

Dickinson, R., Peterson, B. K., Banks, P., Simillis, C., Martin, J. C., Valenzuela, C. A., Maze, M., and Franks, N. P. (2007). Competitive inhibition at the glycine site of the $\mathrm{N}$ methyl-D-aspartate receptor by the anesthetics xenon and isoflurane: evidence from molecular modeling and electrophysiology. Anesthesiology 107, 756-767.

Eger, E. I., Raines, D. E., Shafer, S. L., Hemmings, H. C., and Sonner, J. M. (2008). Is a new paradigm needed to explain how inhaled anesthetics produce immobility? Anesth. Analg. 107, 832-848.

Flood, P., Ramirez-Latorre, J., and Role, L. (1997). Alpha 4 beta 2 neuronal nicotinic acetylcholine receptors in the central nervous system are inhibited by isoflurane and propofol, but alpha 7-type nicotinic acetylcholine receptors are unaffected. Anesthesiology 86, 859-865.

Franks, N. P. (2006). Molecular targets underlying general anaesthesia. $\mathrm{Br}$. J. Pharmacol. 147(Suppl. 1), S72-S81.

Franks, N. P., and Lieb, W. R. (1994). Molecular and cellular mechanisms of general anaesthesia. Nature 367, 607-614.

Haseneder, R., Kratzer, S., Kochs, E., Eckle, V. S., Zieglgansberger, W., and Rammes, G. (2008). Xenon reduces $\mathrm{N}$-methyl-D-aspartate and alpha-amino-3-hydroxy5-methyl-4-isoxazolepropionic acid receptor-mediated synaptic transmission in the amygdala. Anesthesiology 109, 998-1006.

Haydon, D. A., and Simon, A. J. (1988). Excitation of the squid giant axon by general anaesthetics. J. Physiol. (Lond.) 402, 375-389.

Hemmings, H., Yan, W., Westphalen, R., and Ryan, T. (2005a). The general anesthetic isoflurane depresses

Hemmings, H. C. Jr., Akabas, M. H., Goldstein, P. A., Trudell, J. R., Orser, B. A., and Harrison, N. L. (2005b). Emerging molecular mechanisms of general anesthetic action. Trends Pharmacol. Sci. 26, 503-510.

Hemmings, H. C. Jr. (2004). Neuroprotection by $\mathrm{Na}+$ channel blockade. J. Neurosurg. Anesthesiol. 16, 100-101.

Hemmings, H. C., and Adamo, A. I. (1994). Effects of halothane and propofol on purified brain protein kinase $\mathrm{C}$ activation. Anesthesiology $81,147-155$.

Hemmings, H. C., and Adamo, A. I. (1996). Activation of endogenous protein kinase $\mathrm{C}$ by halothane in synaptosomes. Anesthesiology 84, 652-662.

Herold, K. F., Nau, C., Ouyang, W., and Hemmings, H. C. (2009). Isoflurane inhibits the tetrodotoxinresistant voltage-gated sodium channel Nav1.8. Anesthesiology 111, 591-599.

Hodgkin, A., and Huxley, A. (1952). A quantitative description of membrane current and its application to conduction and excitation in nerve. J. Physiol. (Lond.) 117, 500-544.

Horishita, T., Eger, E. I., and Harris, R. A. (2008). The effects of volatile aromatic anesthetics on voltage-gated $\mathrm{Na}+$ channels expressed in Xenopus oocytes. Anesth. Analg. 107, 1579-1586.

Huneke, R., Fassl, J., Rossaint, R., and Luckhoff, A. (2004). Effects of volatile anesthetics on cardiac ion channels. Acta Anaesthesiol. Scand. 48, 547-561.

Kullmann, D. M., Martin, R. L., and Redman, S. J. (1989). Reduction by synaptic vesicle exocytosis. Mol. Pharmacol. 67, 1591-1599.

release and its inhibition by volatile anesthetics and other $\mathrm{Na}^{+}$ channel inhibitors.

\section{ACKNOWLEDGMENTS}

Supported by NIH grant GM58055 (Hugh C. Hemmings Jr.) and DFG (German Research Foundation) grant HE4551/5-1 (Karl F. Herold).

general anaesthetics of group Ia excitatory postsynaptic potentials and currents in the cat spinal cord. $J$. Physiol. (Lond.) 412, 277-296.

Maclver, M. B., Mikulec, A. A., Amagasu, S. M., and Monroe, F. A. (1996). Volatile anesthetics depress glutamate transmission via presynaptic actions. Anesthesiology 85, 823-834.

Meyer, H. (1899). Zur theorie der alkoholnarkose. Arch. Exp. Pathol. Pharmakol. 42, 109-118.

Nicoll, R. A., Eccles, J. C., Oshima, T., and Rubia, F. (1975). Prolongation of hippocampal inhibitory postsynaptic potentials by barbiturates. Nature 258, 625-627.

Nishikawa, K., and MacIver, M. B. (2001). Agent-selective effects of volatile anesthetics on GABAA receptor-mediated synaptic inhibition in hippocampal interneurons. Anesthesiology 94, 340-347.

Orser, B. A. (2006). Extrasynaptic GABAA receptors are critical targets for sedative-hypnotic drugs. J. Clin. Sleep. Med. 2, S12-S18.

Ouanonou, A., Zhang, Y., and Zhang, L. (1999). Changes in the calcium dependence of glutamate transmission in the hippocampal CA1 region after brief hypoxiahypoglycemia. J. Neurophysiol. 82, 1147-1155.

Ouyang, W., and Hemmings, H. (2005). Depression by isoflurane of the action potential and underlying voltage-gated ion currents in isolated rat neurohypophysial nerve terminals. J. Pharmacol. Exp. Ther. 312, 801-808.

Ouyang, W., and Hemmings, $\mathrm{H}$. (2007). Isoform-selective effects of isoflurane on voltage-gated $\mathrm{Na}+$ channels. Anesthesiology 107, 91-98.

Ouyang, W., Herold, K. F., and Hemmings, H. C. (2009). Comparative effects of halogenated inhaled anesthetics on voltage-gated $\mathrm{Na}+$ channel function. Anesthesiology 110, 582-590.

Ouyang, W., Jih, T., Zhang, T., Correa, A. and Hemmings, H. (2007). Isoflurane inhibits $\mathrm{NaChBac}$, a prokaryotic voltage-gated sodium channel. J. Pharmacol. Exp. Ther. 322, 1076-1083.
Ouyang, W., Wang, G., and Hemmings, H. (2003). Isoflurane and propofol inhibit voltage-gated sodium channels in isolated rat neurohypophysial nerve terminals. Mol. Pharmacol. 64, 373-381.

Overton, C. (1901). Studien über die Narkose zugleich ein Beitrag zur allgemeinen Pharmakologie. Jena: Verlag von Gustav Fischer.

Patel, A. J., and Honore, E. (2001). Anesthetic-sensitive 2P domain $\mathrm{K}+$ channels. Anesthesiology 95, 1013-1021.

Perouansky, M., Baranov, D., Salman, M., and Yaari, Y. (1995). Effects of halothane on glutamate receptormediated excitatory postsynaptic currents. A patch-clamp study in adult mouse hippocampal slices. Anesthesiology 83, 109-119.

Rampil, I. J., Mason, P., and Singh, H. (1993). Anesthetic potency (MAC) is independent of forebrain structures in the rat. Anesthesiology 78, 707-712.

Ratnakumari, L., Vysotskaya, T., Duch, D., and Hemmings, H. (2000). Differential effects of anesthetic and nonanesthetic cyclobutanes on neuronal voltage-gated sodium channels. Anesthesiology 92, 529-541.

Rau, V., Iyer, S. V., Oh, I., Chandra, D., Harrison, N., Eger, E. I. II, Fanselow, M. S., Homanics, G. E., and Sonner, J. M. (2009). Gamma-aminobutyric acid type A receptor alpha 4 subunit knockout mice are resistant to the amnestic effect of isoflurane. Anesth. Analg. 109, 1816-1822.

Rehberg, B., and Duch, D. (1999). Suppression of central nervous system sodium channels by propofol. Anesthesiology 91, 512-520.

Rehberg, B., Xiao, Y., and Duch, D. (1996). Central nervous system sodium channels are significantly suppressed at clinical concentrations of volatile anesthetics. Anesthesiology 84, 1223-1233; discussion 1227A.

Richards, C. D., and White, A. E. (1975). The actions of volatile anaesthetics on synaptic transmission in the dentate gyrus. J. Physiol. (Lond.) 252, 241-257.

Rudolph, U., and Antkowiak, B. (2004). Molecular and neuronal substrates for general anaesthetics. Nat. Rev. Neurosci. 5, 709-720. 
Schlame, M., and Hemmings, H. (1995). Inhibition by volatile anesthetics of endogenous glutamate release from synaptosomes by a presynaptic mechanism. Anesthesiology 82, 1406-1416.

Seeman, P. (1974). The actions of nervous system drugs on cell membranes. Hosp. Pract. 9, 93-101.

Shiraishi, M., and Harris, R. (2004). Effects of alcohols and anesthetics on recombinant voltage-gated $\mathrm{Na}+$ channels. J. Pharmacol. Exp. Ther. 309, 987-994.

Sirois, J. E., Lynch, C. III, and Bayliss, D. A. (2002). Convergent and reciprocal modulation of a leak $\mathrm{K}+$ current and $\mathrm{I}(\mathrm{h})$ by an inhalational anaesthetic and neurotransmitters in rat brainstem motoneurones. J. Physiol. (Lond.) 541, 717-729.

Stadnicka, A., Kwok, W. M., Hartmann, H. A., and Bosnjak, Z. J. (1999). Effects of halothane and isoflurane on fast and slow inactivation of human heart hHla sodium channels. Anesthesiology 90, 1671-1683.

Tibbs, G. R., Barrie, A. P., Van Mieghem, F. J., Mcmahon, H. T., and Nicholls, D. G. (1989). Repetitive action potentials in isolated nerve terminals in the presence of 4-aminopyridine: effects on cytosolic free $\mathrm{Ca} 2+$ and glutamate release. J. Neurochem. 53, 1693-1699.
Ulbricht, W. (1998). Effects of veratridine on sodium currents and fluxes. Rev. Physiol. Biochem. Pharmacol. 133, 1-54.

Wakasugi, M., Hirota, K., Roth, S. H., and Ito, Y. (1999). The effects of general anesthetics on excitatory and inhibitory synaptic transmission in area CA1 of the rat hippocampus in vitro. Anesth. Analg. 88, 676-680.

Weakly, J. N. (1969). Effect of barbiturates on "quantal" synaptic transmission in spinal motoneurons. $J$. Physiol. (Lond.) 204, 63-77.

Westphalen, R., and Hemmings, $\mathrm{H}$. (2003). Selective depression by general anesthetics of glutamate versus GABA release from isolated cortical nerve terminals. J. Pharmacol. Exp. Ther. 304, 1188-1196.

Westphalen, R., and Hemmings, $\mathrm{H}$. (2006). Volatile anesthetic effects on glutamate versus GABA release from isolated rat cortical nerve terminals: 4-aminopyridine-evoked release. $J$. Pharmacol. Exp. Ther. 316, 216-223.

Westphalen, R. I., Kwak, N. B., Daniels, K., and Hemmings, H. C. Jr. (2011). Regional differences in the effects of isoflurane on neurotransmitter release. Neuropharmacology 61 699-706.

Westphalen, R. I., Yu, J., Krivitski, M., Jih, T. Y., and Hemmings, H. C. Jr. (2010). Regional differences in nerve terminal $\mathrm{Na}+$ channel subtype expression and $\mathrm{Na}+$ channeldependent glutamate and GABA release in rat CNS. J. Neurochem. 113, 1611-1620.

Wu, X., Sun, J., Evers, A., Crowder, M., and Wu, L. (2004). Isoflurane inhibits transmitter release and the presynaptic action potential. Anesthesiology 100, 663-670.

Xing, Y., Zhang, Y., Stabernack, C. R., Eger, E. I. II, and Gray, A. T. (2003). The use of the potassium channel activator riluzole to test whether potassium channels mediate the capacity of isoflurane to produce immobility. Anesth. Analg. 97, 1020-1024.

Zhang, Y., Guzinski, M., Eger, E. I., Laster, M. J., Sharma, M., Harris, R. A., and Hemmings, H. C. (2010). Bidirectional modulation of isoflurane potency by intrathecal tetrodotoxin and veratridine in rats. Br. J. Pharmacol. 159, 872-878.

Zhang, Y., Laster, M. J., Eger, E. I., Sharma, M., and Sonner, J. M. (2007). Lidocaine, MK-801, and MAC. Anesth. Analg. 104, 1098-1102.

Zhang, Y., Sharma, M., Eger, E. I., Laster, M. J., Hemmings, H. C., and Harris, R. A. (2008). Intrathecal veratridine administration increases minimum alveolar concentration in rats. Anesth. Analg. 107, 875-878.

Zimmerman, S. A., Jones, M. V., and Harrison, N. L. (1994). Potentiation of gamma-aminobutyric acid A receptor $\mathrm{Cl}^{-}$current correlates with in vivo anesthetic potency. J. Pharmacol. Exp. Ther. 270, 987-991.

Conflict of Interest Statement: The authors declare that the research was conducted in the absence of any commercial or financial relationships that could be construed as a potential conflict of interest.

Received: 21 December 2011; paper pending published: 08 January 2012; accepted: 07 March 2012; published online: 30 March 2012.

Citation: Herold KF and Hemmings HC Jr (2012) Sodium channels as targets for volatile anesthetics. Front. Pharmacol. 3:50. doi: 10.3389/fphar.2012.00050

This article was submitted to Frontiers in Pharmacology of Ion Channels and Channelopathies, a specialty of Frontiers in Pharmacology.

Copyright (c) 2012 Herold and Hemmings Jr. This is an open-access article distributed under the terms of the Creative Commons Attribution Non Commercial License, which permits noncommercial use, distribution, and reproduction in other forums, provided the original authors and source are credited. 